\title{
Rustificação de mudas de eucalipto via aplicação de ácido salicílico ${ }^{1}$
}

\author{
Eduardo Henrique Lima Mazzuchelli², Gustavo Maia Souza², Ana Cláudia Pacheco²
}

\begin{abstract}
Hardening of eucalyptus seedlings

via salicylic acid application

The agricultural and forest productivity suffer restrictions imposed by water stress, high temperature and high solar radiation. This study aimed to evaluate the capacity of stress attenuation and growth promotion of salicylic acid (SA) application in eucalyptus (E. urophylla x E. grandis hybrid) seedlings under water stress. A completely randomized design, in a $3 \times 4$ factorial scheme (three water treatments: constant irrigation with daily replacement of $40 \%$ (CI40\%) or $100 \%$ (CI100\%) of evapotranspirated water, and temporary irrigation suspension with replacement of only $40 \%$ of evapotranspirated water (S40\%); and four SA concentrations: $0 \mathrm{mg} \mathrm{L}^{-1}, 100 \mathrm{mg} \mathrm{L}^{-1}$, $200 \mathrm{mg} \mathrm{L}^{-1}$ and $300 \mathrm{mg} \mathrm{L}^{-1}$ ), was used. Plant photosynthetic parameters and biometric features were evaluated. The stomatal limitation was higher in plants under S40\% irrigation, however, the SA application reverted this result, allowing the maintenance of the photosynthetic potential. There was interaction between irrigation regimes and SA doses for number of leaves, leaf area/number of leaves ratio and shoot and root dry mass. It was concluded that the application of $200 \mathrm{mg} \mathrm{L}^{-1}$ of SA positively affected the growth of eucalyptus seedlings under water stress, being considered an auxiliary management technique to their hardening process.
\end{abstract}

KEY-WORDS: Eucalyptus sp; water stress; growth regulator.

\section{INTRODUÇÃO}

O uso de material genético de eucalipto (Eucalyptus sp.) capaz de se estabelecer e desenvolver em condições de deficiência hídrica no solo pode ser de fundamental importância para o êxito de um povoamento florestal.

Plantas expostas a deficiência hídrica apresentam disfunções bioquímicas e fisiológicas, tais como redução de turgor e de crescimento, redução da

\section{RESUMO}

A produtividade agronômica e florestal sofrem restrições impostas pela deficiência hídrica, alta temperatura e alta radiação solar. Este trabalho objetivou avaliar as capacidades de atenuação do estresse e promoção de crescimento da aplicação de ácido salicílico (AS) a mudas de eucalipto (híbrido E. urophylla x E. grandis) submetidas a deficiência hídrica. Adotou-se o delineamento experimental inteiramente casualizado, em esquema fatorial $3 \times 4$ (três regimes de irrigação: irrigação constante com $40 \%$ (IC40\%) ou 100\% (IC100\%) de reposição diária da água evapotranspirada e suspensão temporária da irrigação com apenas $40 \%$ de reposição da água evapotranspirada (S40\%); e quatro concentrações de AS: $0 \mathrm{mg} \mathrm{L}^{-1}, 100 \mathrm{mg} \mathrm{L}^{-1}, 200 \mathrm{mg} \mathrm{L}^{-1}$ e $300 \mathrm{mg} \mathrm{L}^{-1}$ ). Foram avaliados parâmetros fotossintéticos das plantas e características biométricas de crescimento. A limitação estomática foi maior nas plantas submetidas ao regime de irrigação $\mathrm{S} 40 \%$, entretanto, a aplicação de AS reverteu esse resultado, permitindo a manutenção do potencial fotossintético. Houve interação entre regimes de irrigação e doses de AS para número de folhas, relação área foliar/ número de folhas e massa seca da parte aérea e raiz. Concluiuse que a aplicação de $200 \mathrm{mg} \mathrm{L}^{-1}$ de AS afetou positivamente o crescimento das mudas de eucalipto sob condição de deficiência hídrica, constituindo-se como técnica de manejo auxiliar para o seu processo de rustificação.

PALAVRAS-CHAVES: Eucalyptus sp.; deficiência hídrica; regulador vegetal.

atividade fotossintética e da condutância estomática e danos aos componentes celulares (Janda et al. 2007).

Para tornar as plantas mais resistentes a variações nas condições ambientais, os viveiros florestais realizam a rustificação de mudas, que consiste em suspender e diminuir, progressivamente, o tempo de irrigação das mudas, ainda no viveiro, o que possibilita menores perdas, quando da transferência das plantas para o campo. Por isso, a identificação de genótipos resistentes para implantação em condições

1. Trabalho recebido em dez./2013 e aceito para publicação em dez./2014 ( $\mathrm{n}^{\circ}$ registro: PAT 27723).

2. Universidade do Oeste Paulista (Unoeste), Presidente Prudente, SP, Brasil.

E-mails: eduardo_mazzuchelli@hotmail.com,gustavo@unoeste.br, anaclau@unoeste.br. 
ambientais adversas, especialmente em relação à deficiência hídrica no solo, é um desafio para muitas empresas florestais (Tatagiba et al. 2007).

Estudos recentes têm dado considerável importância à habilidade de o ácido salicílico (AS) induzir efeitos de proteção (adaptação e resistência), em plantas sob estresse hídrico. O AS é um hormônio vegetal de natureza fenólica, que exerce diferentes funções regulatórias no metabolismo das plantas. A aplicação exógena de AS, em baixas concentrações $\left(10^{-3}-10^{-6} \mathrm{M}\right)$, exerce efeito determinante na indução de tolerância, em plantas expostas ao estresse hídrico, como verificado em tomate (Hayat et al. 2008), feijão (Senaratna et al. 2000), aveia (Bandurska \& Stroinski 2005) e girassol (Hussain et al. 2008).

Os efeitos atribuídos ao AS, como agente mitigador do estresse hídrico, compreendem desde os aumentos na capacidade antioxidante da planta e na estabilidade das membranas pelo decréscimo no nível de peroxidação de lipídios (Agarwal et al. 2005), até aumentos na capacidade fotossintética (Khan et al. 2003) e no acúmulo de biomassa (Singh \& Usha 2003). Dessa maneira, sugere-se que a aplicação de AS a mudas de eucalipto pode se constituir em tecnologia auxiliar no processo de rustificação das mesmas, com consequente redução nos custos de plantio e manejo.

Diante do exposto, este trabalho foi proposto com o objetivo de avaliar o efeito da aplicação exógena de AS a mudas de eucalipto submetidas a deficiência hídrica, quanto ao seu potencial de atenuação do estresse e promoção do crescimento.

\section{MATERIAL E MÉTODOS}

A pesquisa foi conduzida em área experimental da Universidade do Oeste Paulista (Unoeste), em Presidente Prudente (SP), de junho a novembro de 2012.

Foram utilizadas 240 mudas, com 45 dias de idade, do híbrido Eucalyptus urophylla $\mathrm{x}$ Eucalyptus grandis (clone H13), obtidas pelo processo de miniestaquia e cedidas pela empresa Pontal Flora, as quais foram produzidas em tubetes de $55 \mathrm{~cm}^{3}(3 \mathrm{~cm}$ diâmetro x $10 \mathrm{~cm}$ altura), com substrato comercial Bioplant (composto por casca de pinus e vermiculita na proporção 1:1). Antes do início do experimento, as mudas passaram por um período de aclimatação, durante 10 dias, sendo dispostas em bancadas ao ar livre, cobertas por sombrite $50 \%$ apenas nos horários de maior incidência solar (das 10 às 16h). A irrigação foi realizada por microaspersor (Agrojet, modelo bailarina com pressão de 10 mca e vazão média de $52 \mathrm{~L} \mathrm{hora}^{-1}$ ), em 4 turnos diários de rega de 10 minutos cada. A temperatura média registrada nesse período foi de $22^{\circ} \mathrm{C}$.

Na Fase 1 do experimento, as mudas foram divididas em dois grupos e submetidas a condições de irrigação constante (IC) ou suspensão temporária da irrigação (S), com a finalidade de se iniciar a imposição de deficiência hídrica às plantas, na fase de mudas ainda em tubetes. Na condição IC, as mudas foram mantidas sob irrigação por microaspersão, durante um período de 18 dias. Na condição $\mathrm{S}$, as mudas receberam irrigação durante 3 dias, seguidos de um dia de interrupção da irrigação, de maneira alternada, até que se completassem 18 dias. Em ambas as condições de irrigação, as mudas receberam aplicação de AS ao término do período ( $18^{\circ}$ dia $)$, nas doses de $100 \mathrm{mg} \mathrm{L}^{-1}, 200 \mathrm{mg} \mathrm{L}^{-1}$ e $300 \mathrm{mg} \mathrm{L}^{-1}$, via pulverização foliar (até o ponto de gotejamento), utilizando-se adjuvante (Tween 80 ).

Na Fase 2, as mudas foram transplantadas para vasos de $8 \mathrm{dm}^{3}$, contendo solo Vermelho-Amarelo distroférrico. As características químicas do solo foram determinadas segundo Raij et al. (2001) e apresentaram os seguintes resultados: $\mathrm{P}($ resina $)=$ $24 \mathrm{mg} \mathrm{dm}{ }^{-3} ; \mathrm{MO}=5 \mathrm{mg} \mathrm{dm}^{-3} ; \mathrm{pH}\left(\mathrm{CaCl}_{2}\right)=6,3$; $\mathrm{K}^{+}=2,2 \mathrm{mmol}_{\mathrm{c}} \mathrm{dm}^{-3} ; \mathrm{Ca}^{++}=19 \mathrm{mmol}_{\mathrm{c}} \mathrm{dm}^{-3} ; \mathrm{Mg}^{++}=$ $14 \mathrm{mmol} \mathrm{dm}^{-3} ; \mathrm{Al}^{+3}=0 \mathrm{mmol} \mathrm{dm}{ }^{-3} ; \mathrm{V} \%=68 ; \mathrm{e} \mathrm{m} \%=$ 0 (percentagem de saturação por alumínio). O solo não recebeu adubação e nem calagem, por apresentar V\% próximo a $70 \%$ e teores de nutrientes adequados (Raij et al. 1996).

As plantas foram cultivadas em casa-de-vegetação, durante um período de 117 dias após o transplantio (DAT). As plantas provenientes da condição IC foram subdivididas em dois grupos, recebendo $40 \%$ ou $100 \%$ de reposição diária da água evapotranspirada (IC100\% e IC40\%). As plantas provenientes da condição $\mathrm{S}$ permaneceram recebendo apenas $40 \%$ de reposição da água evapotranspirada (S40\%). Nessa fase, todas as plantas receberam uma segunda aplicação de AS, nas doses de $0 \mathrm{mg} \mathrm{L}^{-1}$, $100 \mathrm{mg} \mathrm{L}^{-1}, 200 \mathrm{mg} \mathrm{L}^{-1}$ e $300 \mathrm{mg} \mathrm{L}^{-1}$.

A reposição de água foi realizada pelo método gravimétrico (Catuchi et al. 2011), que consiste na determinação do peso do vaso na capacidade de campo (após saturação do solo com água e drenagem completa verificada pela estabilização do peso) e sua 
utilização como valor de referência para a irrigação diária dos vasos, de acordo com o seguinte modelo: a) Reposição $100 \%$ = peso do vaso controle na capacidade de campo - peso do vaso controle no dia seguinte $\times 1,0$; b) Reposição $40 \%=$ peso do vaso controle na capacidade de campo - peso do vaso controle no dia seguinte x 0,4 .

A temperatura e umidade relativa internas da casa-de-vegetação foram monitoradas diariamente, por registrador de dados $\mathrm{HOBO}$ (modelo $\mathrm{HO} 8-004-$ 02 , EUA), para coleta de temperatura $\left(\mathrm{T}^{\circ} \mathrm{C}\right)$. As temperaturas médias registradas durante o período foram de $30^{\circ} \mathrm{C} \pm 2^{\circ} \mathrm{C}$ e a umidade relativa média foi de $50 \%$.

Adotou-se o delineamento experimental inteiramente casualizado, em esquema fatorial $3 \times 4$ (três regimes de irrigação: IC100\%, IC40\% e S40\%; e quatro concentrações de AS: $0 \mathrm{mg} \mathrm{L}^{-1}, 100 \mathrm{mg} \mathrm{L}^{-1}, 200 \mathrm{mg} \mathrm{L}^{-1}$ e $300 \mathrm{mg} \mathrm{L}^{-1}$ ), com 12 tratamentos e 8 repetições.

O potencial fotossintético foi avaliado aos 80 dias após o transplantio, por meio de curvas de resposta ao $\mathrm{CO}_{2}$ (curvas $\mathrm{A} / \mathrm{Ci}$, em que A corresponde à assimilação máxima de $\mathrm{CO}_{2}$ e $\mathrm{Ci}$ à concentração intercelular de $\mathrm{CO}_{2}$ ). As curvas $\mathrm{A} / \mathrm{Ci}$ foram realizadas variando-se a concentração de $\mathrm{CO}_{2}$ ambiente, dentro da câmara de amostragem de um analisador de gases por infravermelho (Li-6400XTR, LiCor, EUA). As medidas foram realizadas sob irradiância saturante (1.200 $\mu \mathrm{mol}$ de fótons $\left.\mathrm{m}^{-2} \mathrm{~s}^{-1}\right)$, umidade do ar mantida a $60 \%$, com um gerador de ponto de orvalho (modelo Li-610, Li-Cor) acoplado ao Li-6400XTR, e temperatura de $30^{\circ} \mathrm{C}$. Foram avaliadas quatro plantas por tratamento.

As curvas foram ajustadas conforme modelo proposto por Sharkey et al. (2007), calculando-se a taxa máxima de carboxilação da rubisco (Vcmax), fotossíntese potencial $\left(A \max \mathrm{CO}_{2}\right)$, ponto de compensação ao $\mathrm{CO}_{2}$ (Pcom) e ponto de saturação ao $\mathrm{CO}_{2}$ (Psat). A limitação estomática relativa da fotossíntese (LS) foi calculada segundo Farquhar \& Sharkey (1982), como LS = [(A'-A)/A']*100, em que A' corresponde à taxa de assimilação de $\mathrm{CO}_{2}$, assumindo-se a resistência à difusão do $\mathrm{CO}_{2}$ como zero, e $\mathrm{A}$ é a taxa atual de assimilação de $\mathrm{CO}_{2}$.

Aos 100 dias após o plantio, foram avaliadas as características biométricas de altura de plantas, número de folhas (NF), área foliar (AF), massa seca da parte aérea (MSPA), massa seca da raiz (MSR), relação entre a massa de matéria seca da raiz e massa seca da parte aérea (R/PA) e razão entre a área foliar e o número de folhas (AF/NF).
A AF foi determinada com medidor portátil de área foliar (modelo LI-3000A, Li-Cor, USA). A MSPA e MSR foram determinadas após a secagem das plantas em estufa, a $65^{\circ} \mathrm{C}$, até a obtenção de peso constante.

Os parâmetros avaliados foram submetidos à análise de variância (Anova), utilizando-se o programa Sisvar (Ferreira 2010). Por se tratar de experimento fatorial (fator 1: regimes de irrigação caráter qualitativo; fator 2: concentrações de AS caráter quantitativo), primeiramente foi realizada a Anova para verificação da significância de cada fator, isoladamente ou em interação. $\mathrm{O}$ desdobramento de cada fator, em relação ao outro, ocorreu com a comparação de médias por teste Tukey a 5\% (para o fator 1) e análise de regressão, optando-se pelo modelo com maior coeficiente de determinação - $\mathrm{R}^{2}$ (para o fator 2). Os dados referentes ao número de folhas foram transformados em raiz quadrada, para $\mathrm{o}$ atendimento das pressuposições estatísticas para a realização da Anova.

\section{RESULTADOS E DISCUSSÃO}

Os parâmetros fotossintéticos analisados não foram influenciados pelas concentrações de AS utilizadas e regimes de irrigação impostos às plantas de eucalipto (Tabela 1). Possivelmente, a reposição de $40 \%$ da evapotranspiração se caracterizou em uma intensidade moderada de estresse hídrico não suficiente para provocar alterações nos processos fotossintéticos como um todo.

A LS foi maior nas plantas de eucalipto submetidas a deficiência hídrica nas fases 1 e 2 (S40\%), entretanto, a aplicação de AS foi capaz de reverter esse resultado nas três concentrações testadas (Figura 1). A LS está relacionada ao potencial dos estômatos em limitar a assimilação de $\mathrm{CO}_{2}$ e, consequentemente, a produção de trioses fosfatos (Souza et al. 2004). Portanto, os menores valores de LS observados nas plantas tratadas com AS indicam ocorrência de baixa limitação fotossintética, o que pode ter colaborado para a manutenção dos parâmetros fotossintéticos das plantas, mesmo com a imposição de deficiência hídrica (Tabela 1). A reversão do fechamento estomático induzido pelo ácido abscísico (ABA), em decorrência da aplicação de AS a plantas sob estresse hídrico, também foi relatada por Rai et al. (1986), porém, essa resposta não é padrão para todas as culturas. 
Tabela 1. Assimilação máxima de $\mathrm{CO}_{2}$, velocidade máxima de carboxilação e ponto de saturação de compensação ao $\mathrm{CO}_{2}$ de plantas de eucalipto (híbrido E. urophylla x E. grandis), em função da aplicação de doses de ácido salicílico e regimes de irrigação (Presidente Prudente, SP, 2012).

\begin{tabular}{|c|c|c|c|c|}
\hline $\begin{array}{c}\text { Dose de ácido } \\
\text { salicílico }\end{array}$ & $\begin{array}{c}\text { Assimilação máxima } \\
\text { de } \mathrm{CO}_{2}\end{array}$ & $\begin{array}{l}\text { Velocidade máxima de } \\
\text { carboxilação }\end{array}$ & $\begin{array}{c}\text { Ponto de saturação } \\
\text { ao } \mathrm{CO}_{2}\end{array}$ & $\begin{array}{c}\text { Ponto de compensação } \\
\text { ao } \mathrm{CO}_{2}\end{array}$ \\
\hline $\mathrm{mg} \mathrm{L}^{-1}$ & \multicolumn{2}{|c|}{$\mu \mathrm{mol} \mathrm{CO} \mathrm{m}^{-2} \mathrm{~s}^{-1}$} & \multicolumn{2}{|c|}{$\mu \mathrm{mol} \mathrm{mol}^{-1}$} \\
\hline 0 & 14,28 & 86,38 & 893,58 & 83,10 \\
\hline 100 & 16,18 & 82,16 & 932,27 & 82,83 \\
\hline 200 & 13,79 & 81,69 & 703,74 & 87,08 \\
\hline 300 & 10,72 & 80,73 & 583,89 & 62,50 \\
\hline $\mathrm{F}$ & $0,89^{\text {ns }}$ & $0,18^{\mathrm{ns}}$ & $1,16^{\mathrm{ns}}$ & $0,60^{\mathrm{ns}}$ \\
\hline \multicolumn{5}{|c|}{ Regime de irrigação } \\
\hline IC $100 \%$ & 14,72 & 79,18 & 922,27 & 85,33 \\
\hline IC40\% & 11,63 & 90,43 & 740,50 & 67,68 \\
\hline $\mathrm{S} 40 \%$ & 14,88 & 78,49 & 671,64 & 83,61 \\
\hline $\mathrm{F}$ & $0,77^{\text {ns }}$ & $1,76^{\mathrm{ns}}$ & $0,98^{\text {ns }}$ & $0,62^{\text {ns }}$ \\
\hline
\end{tabular}

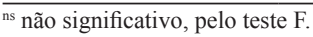

Os regimes de irrigação e o AS exerceram efeitos isolados sobre a altura e a área foliar das plantas. Sob irrigação constante (IC100\%), as plantas apresentaram maior altura e área foliar, em relação às plantas submetidas à suspensão da irrigação somente na fase 2 (IC40\%) e nas fases 1 e 2 (S40\%) (Tabela 2). Com relação à aplicação de $\mathrm{AS}$, verificou-se que houve aumento na altura das plantas para todas as concentrações utilizadas, entretanto, somente a concentração de $300 \mathrm{mg} \mathrm{L}^{-1}$ de AS foi eficiente em promover aumento de área foliar (Figura 2).

Sugerem-se vários mecanismos por meio dos quais o AS afeta positivamente a produção de biomassa nas plantas. Dentre eles, é relatada a existência de interações cruzadas entre o AS e outros fitormônios, na regulação gênica. Ao atuar em coordenação com citocininas, etileno, auxinas, giberelinas, ácido jasmônico e ácido abscísico, o AS contribui, de forma importante, na regulação do crescimento e desenvolvimento da planta, embora os mecanismos bioquímicos que medeiam a maioria dessas respostas permaneçam amplamente desconhecidos (Rivas-San Vicent \& Plasencia 2011). Adicionalmente, a aplicação exógena de AS pode modificar o status hormonal da planta, pelo aumento no conteúdo endógeno de giberelinas (Kim et al. 2009) ou auxinas (Shakirova et al. 2003).

Entre as alterações fisiológicas e bioquímicas das plantas, em resposta à aplicação de AS, são, também, citados aumentos no conteúdo de pigmentos fotossintéticos (clorofilas e carotenoides), em plantas sob condição normal ou estressante (Singh \& Usha 2003, Khodary 2004), e na atividade da enzima nitrato redutase (Fariduddin et al. 2003).
Tabela 2. Efeito de diferentes regimes de irrigação sobre a altura e área foliar de plantas de eucalipto (híbrido E. urophylla x E. grandis) (Presidente Prudente, SP, 2012).

\begin{tabular}{lcc}
\hline \multicolumn{1}{c}{ Regime de } & Altura & Área foliar \\
\cline { 2 - 3 } irrigação & $\mathrm{cm}$ & $\mathrm{cm}^{2}$ \\
\hline $\mathrm{IC} 100 \%$ & $70,38 \mathrm{a}^{1}$ & $1.698,73 \mathrm{a}$ \\
$\mathrm{IC} 40 \%$ & $63,21 \mathrm{~b}$ & $1.082,51 \mathrm{~b}$ \\
$\mathrm{~S} 40 \%$ & $63,38 \mathrm{~b}$ & $1.080,08 \mathrm{~b}$ \\
\hline $\mathrm{F}$ & $31,18^{*}$ & $61,67^{*}$ \\
\hline
\end{tabular}

${ }^{1}$ Letras minúsculas diferentes, nas colunas, indicam diferenças estatísticas $(\mathrm{p}<$ $0,05)$, pelo teste Tukey.

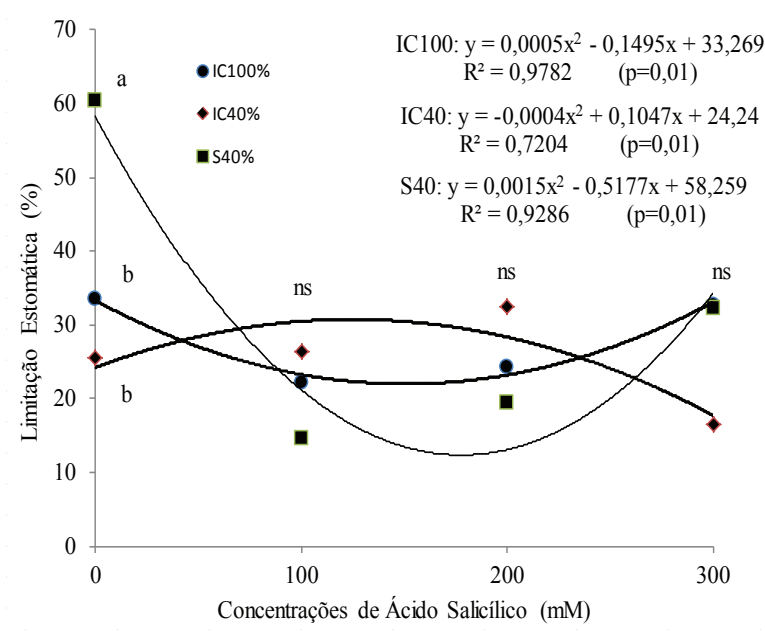

Figura 1. Interação entre os fatores regime de irrigação e concentração de ácido salicílico sobre a limitação estomática (LS), em folhas de eucalipto (híbrido E. urophylla $\mathrm{x}$ E. grandis) submetido a deficiência hídrica (Presidente Prudente, SP, 2012). Letras distintas indicam diferença significativa a $5 \%$, entre os regimes de irrigação, dentro de cada concentração de AS, e ns = não significativo. 

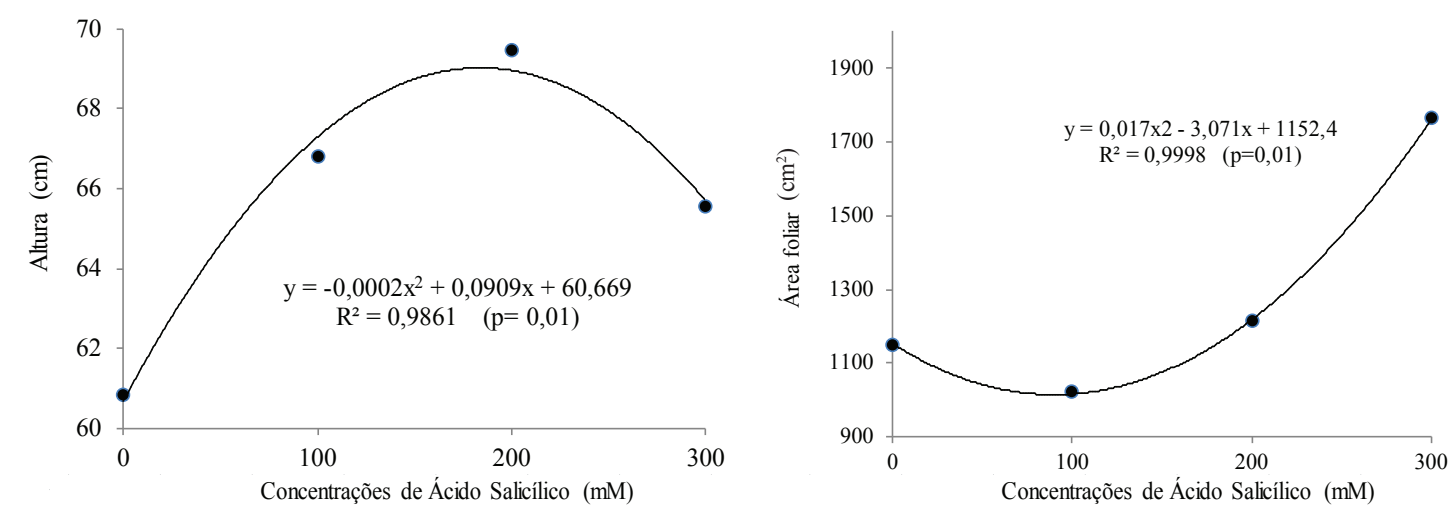

Figura 2. Efeito das concentrações de ácido salicílico sobre a altura e área foliar de plantas de eucalipto (híbrido E. urophylla $\mathrm{x}$ E. grandis) submetidas a deficiência hídrica (Presidente Prudente, SP, 2012).

Em relação aos parâmetros número de folhas e relação área foliar/número de folhas, verificou-se interação entre os regimes de irrigação e as concentrações de AS (Figura 3). Quando a deficiência hídrica foi imposta apenas na fase 2 (IC40\%), o número de folhas produzidas por planta foi mantido com a aplicação de $100 \mathrm{mg} \mathrm{L}^{-1}$ e $200 \mathrm{mg} \mathrm{L}^{-1}$ de AS. Já quando a condição de deficiência hídrica ocorreu nas fases 1 e 2 (S40\%), a aplicação de AS foi eficiente em impedir a redução no número de folhas, para todas as dosagens testadas. Em decorrência disso, observou-se que a relação entre a área foliar e o número de folhas foi mantida nas plantas sob deficiência hídrica (IC40\% e $\mathrm{S} 40 \%$ ), quando comparadas às plantas hidratadas (IC100\%), verificando-se comportamento quadrático de aumento nessa variável, em relação ao aumento das concentrações de AS testadas (Figura 3), com valores maiores na concentração de $300 \mathrm{mg} \mathrm{L}^{-1}$ de AS. Esses resultados estão em concordância com as observações de Agarwal et al. (2005), no caso de genótipos de trigo sob estresse hídrico, em que o tratamento das plantas com AS resultou em atenuação do estresse, refletindo em aumentos de área foliar e biomassa total, em relação às plantas não tratadas.

Ao se avaliarem os valores de MSPA e MSR, verificou-se a ocorrência de interação entre os fatores regime de irrigação e concentração de AS (Figura 4). Na comparação entre regimes de irrigação, observou-se redução da MSPA nas plantas sob deficiência hídrica, independentemente da aplicação de AS. As reduções no número de folhas e na área foliar, em decorrência do estresse hídrico, implicaram em menor ganho total de carbono, o que explica a diminuição de biomassa aérea, mesmo com a ausência de variação nos parâmetros fotossintéticos.
A aplicação de $200 \mathrm{mg} \mathrm{L}^{-1}$ de AS foi eficiente em aumentar os valores de MSPA, em relação às plantas controle $\left(0 \mathrm{mg} \mathrm{L}^{-1}\right)$, quando a condição de de-
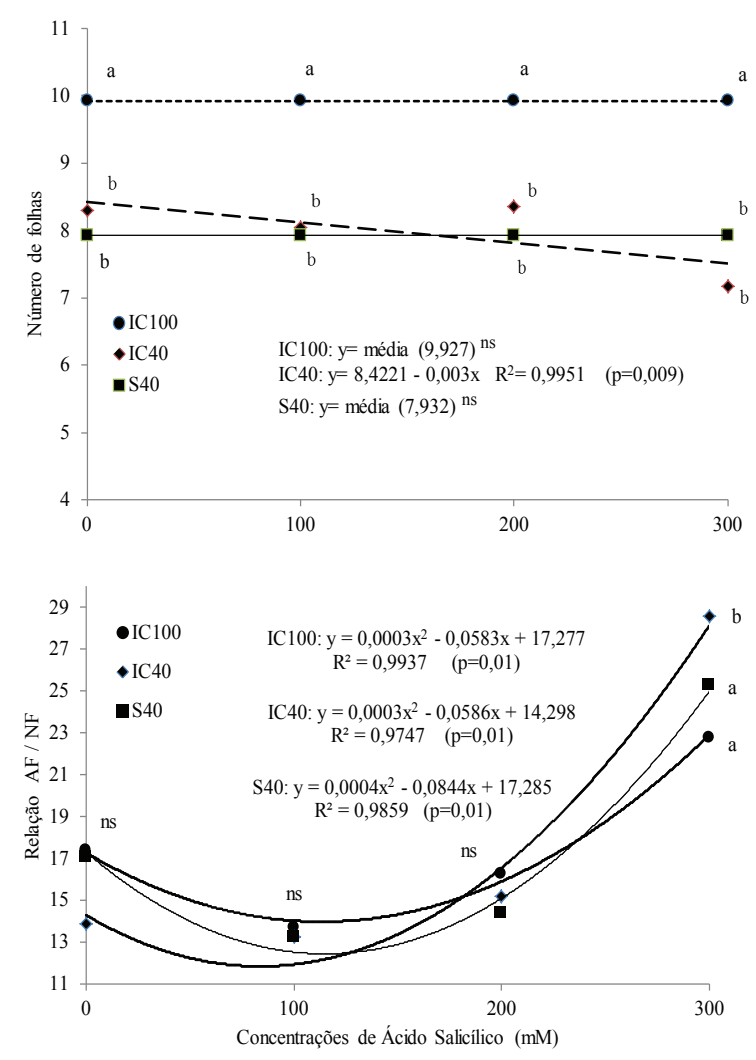

Figura 3. Interação entre os fatores regime de irrigação e concentrações de ácido salicílico sobre o número de folhas e relação área foliar/número de folhas (AF/NF), em plantas de eucalipto (híbrido E. urophylla x E. grandis) submetidas a deficiência hídrica (Presidente Prudente, SP, 2012). Letras distintas indicam diferença significativa a $5 \%$ entre os regimes de irrigação, dentro de cada concentração de $\mathrm{AS}$, e ns = não significativo. 

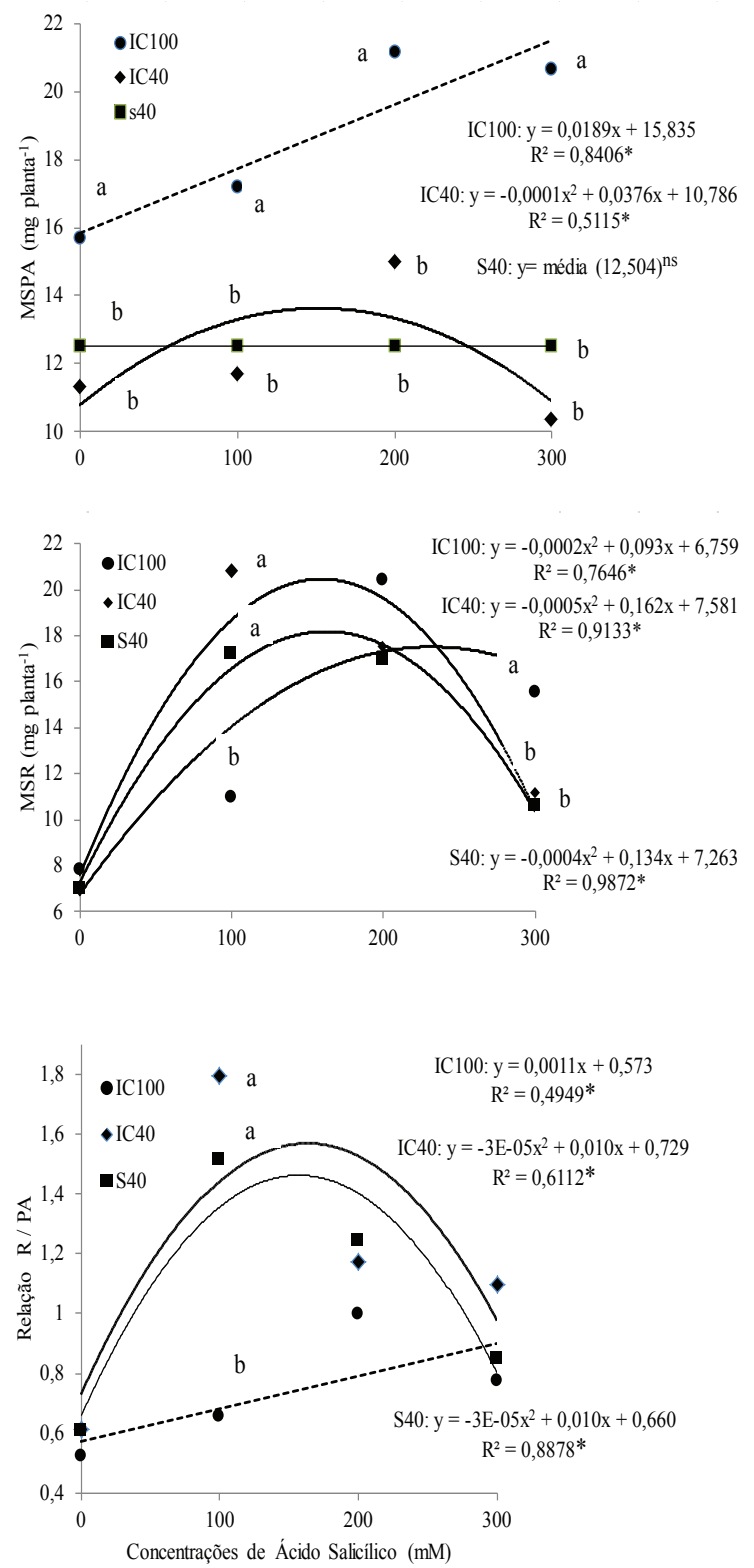

Figura 4. Interação entre os fatores regime de irrigação e concentrações de ácido salicílico sobre a massa seca da parte aérea, massa seca de raízes e relação raiz/parte aérea, em plantas de eucalipto (híbrido E. urophylla $\mathrm{x}$ E. grandis) submetidas a deficiência hídrica (Presidente Prudente, SP, 2012). Letras distintas indicam diferença significativa a 5\%, entre os regimes de irrigação, dentro de cada concentração de AS, e ns = não significativo.

ficiência hídrica ocorreu somente na fase 2 (IC40\%), possivelmente por essa condição se caracterizar como um estresse menos prolongado, em relação ao tratamento $\mathrm{S} 40 \%$.

Para a MSR, a aplicação de $100 \mathrm{mg} \mathrm{L}^{-1}$ de AS resultou em maiores valores nas plantas sob deficiência hídrica (IC40\% e S40\%), quando comparadas às plantas hidratadas (Figura 4). Ao se comparar o efeito das diferentes concentrações de AS nas plantas sob deficiência hídrica (IC40\% e S40\%), verificaram-se aumentos significativos na MSR das plantas tratadas com $100 \mathrm{mg} \mathrm{L}^{-1}$ e $200 \mathrm{mg} \mathrm{L}^{-1}$ de AS.

Comparando-se o efeito das diferentes concentrações de AS nas plantas hidratadas, observou-se aumentos lineares da MSPA, conforme houve aumento da concentração de AS aplicada (Figura 4). Já nas plantas com IC40\%, verificou-se comportamento quadrático da MSPA, em função do aumento da concentração de AS, com ponto máximo para a dose de $188 \mathrm{mg} \mathrm{L}^{-1}$.

A MSR apresentou comportamento quadrático, em função da concentração de AS aplicada, para todos os regimes de irrigação testados (Figura 4). De acordo com Larqué-Saavedra \& Martin-Mex (2007), a ação positiva do AS sobre o comprimento e a densidade de raízes é determinante para o aumento de produtividade nas plantas tratadas.

Sugere-se que os incrementos de biomassa observados em plantas tratadas com AS podem ter resultado de uma ação direta desse composto sobre a diferenciação tecido-específica e o crescimento de órgãos vegetais. O AS pode interagir de forma harmônica com outros hormônios da planta ou ter a sua ação regulada por eles (Joseph et al. 2010).

A relação entre raízes e parte aérea $(\mathrm{R} / \mathrm{PA}$; Figura 4) foi maior nas plantas tratadas com $100 \mathrm{mg} \mathrm{L}^{-1}$ de AS, na condição de deficiência hídrica (IC40\% e $\mathrm{S} 40 \%$ ), em comparação às plantas hidratadas (IC100\%), como consequência do aumento na MSR. Na comparação entre as concentrações de AS, verificou-se tendência quadrática de aumento da relação R/PA, nas plantas submetidas a deficiência hídrica (Figura 4). Já nas plantas hidratadas (IC100\%), houve aumento linear da relação R/PA conforme o aumento da concentração de AS utilizada. O incremento no crescimento radicular, em detrimento do crescimento da parte aérea, é uma resposta comumente observada em plantas sob condição de estresse hídrico (Larcher 2004), possibilitando a absorção de água pelas raízes em camadas mais profundas do solo.

Os resultados deste experimento indicam que a aplicação de AS poderia afetar positivamente o crescimento e desenvolvimento de mudas de eucalipto, sendo esse efeito observado tanto em condição normal como sob condição de estresse hídrico. OAS atua duplamente como fitoregulador e como agente mitigador do estresse hídrico. O efeito hormonal 
de estímulo ao crescimento ocorre pela interação positiva entre o AS e outros fitormônios (auxinas, giberelinas, citocininas e etileno) relacionados aos diferentes processos fisiológicos das plantas (Rivas-San Vicente \& Plasencia 2011), muito embora esse mecanismo de ação ainda não esteja bem elucidado (Joseph et al. 2010).

A ação atenuadora de estresse ocorre pela prevenção de dano oxidativo celular via aumento da atividade de enzimas antioxidantes (Agarwal et al. 2005, Joseph et al. 2010), além da diminuição da peroxidação de lipídios da membrana celular (Gunes et al. 2007). Associado à manutenção da homeostase redox das células, o efeito de atenuação de estresse exercido pelo AS também pode ocorrer pela indução de uma via respiratória alternativa (Moore et al. 2002), na qual o aumento da atividade da enzima oxidase alternativa é estimulado por condições estressantes e funciona como mecanismo que visa a reduzir a formação de espécies reativas de oxigênio.

\section{CONCLUSÃO}

A aplicação foliar de ácido salicílico $\left(200 \mathrm{mg} \mathrm{L}^{-1}\right)$ a mudas de eucalipto sob deficiência de água resultou em atenuação nos efeitos negativos do estresse hídrico sobre o crescimento das plantas, constituindo-se em técnica de manejo eficiente para auxiliar no processo de rustificação das plantas.

\section{AGRADECIMENTOS}

Ao Conselho Nacional de Desenvolvimento Científico e Tecnológico (CNPq), pelas bolsas de Iniciação Científica e Produtividade concedidas ao primeiro e segundo autores, respectivamente.

\section{REFERÊNCIAS}

AGARWAL, S. et al. Changes in antioxidant enzymes activity and oxidative stress by abscisic acid and salicylic acid in wheat genotypes. Biologia Plantarum, Copenhagen, v. 49, n. 4, p. 541-550, 2005.

BANDURSKA, H.; STROINSKI, A. The effect of salicylic acid on barley response to water deficit. Acta Physiologia Plantarum, Cracóvia, v. 27, n. 3b, p. 379-386, 2005.

CATUCHI, T. A. et al. Tolerance to water deficiency between two soybean cultivars: transgenic versus conventional. Ciência Rural, Santa Maria, v. 31, n. 3, p. 373-378, 2011.
FARIDUDDIN, Q.; HAYATH, S.; AHMAD, A. Salicylic acid influences net photosynthetic rate, carboxylation efficiency, nitrate reductase activity and seed yield in Brassica juncea. Photosynthetica, Praga, v. 41, n. 2, p. 281284, 2003.

FARQUHAR, G. D.; SHARKEY, T. D. Stomatal conductance and photosynthesis. Annual Review of Plant Physiology, Boca Raton, v. 33, n. 1, p. 317-345, 1982.

FERREIRA, D. F. Sisvar: sistema de análise de variância. Versão 5.3. Lavras: UFLa, 2010.

GUNES, A. et al. Salicylic acid induced changes on some physiological parameters symptomatic for oxidative stress and mineral nutrition in maize (Zea mays L.) grown under salinity. Journal of Plant Physiology, Stuttgart, v. 164, n. 6, p. 728-736, 2007.

HAYAT, S. et al. Growth of tomato (Lycopersicon esculentum) in response to salicylic acid under water stress. Journal of Plant Interactions, Berlin, v. 3, n. 4, p. 297-304, 2008.

HUSSAIN, M. et al. Improving drought tolerance by exogenous application of glycinebetaine and salicylic acid in sunflower. Journal of Agronomy \& Crop Science, New York, v. 194, n. 3, p. 193-199, 2008.

JANDA, T. et al. Role of salicylic acid in the induction of abiotic stress tolerance. In: HAYAT, S.; AHMAD, A. (Eds.). Salicylic acid: a plant hormone. Dordrecht: Springer, 2007. p. 91-150.

JOSEPH, B.; JINI, D.; SUJATHA, S. Insight into the role of exogenous salicylic acid on plants grown under salt environment. Asian Journal of Crop Science, Faisalabad, v. 2, n. 4, p. 226-235, 2010.

KHAN, W.; PRITHVIRAJ, B.; SMITH, D. L. Photosynthetic responses of corn and soybean to foliar application of salicylates. Journal of Plant Physiology, Stuttgart, v. 160, n. 5, p. 485-492, 2003.

KIM, Y. H. et al. Exogenous application of plant growth regulators increased the total flavonoid content in Taraxacum officinale (Wigg). African Journal of Biotechnology, Bowie, v. 8, n. 21, p. 5727-5732, 2009.

KHODARY, S. E. A. Effect of salicylic acid on growth, photosynthesis and carbohydrate metabolism in salt stressed maize plants. International Journal of Agriculture and Biology, Faisalabad, v. 6, n. 1, p. 5-8, 2004.

LARCHER, W. Ecofisiologia Vegetal. São Carlos: RiMa, 2004.

LARQUÉ-SAAVEDRA, A.; MARTIN-MEX, R. Effects of salicylic acid on bioproductivity of plants. In: HAYAT, S.; AHMAD, A. (Eds.). Salicylic acid: a plant hormone. Dordrecht: Springer, 2007. p. 15-23. 
MOORE, A. L. et al. Function of the alternative oxidase: is it still a scavenger? Trends in Plant Science, Oxford, v. 7, n. 11, p. 478-481, 2002.

RAI, V. K.; SHARMA, S. S.; SHARMA, S. Reversal of ABA-induced stomatal closure by phenolic compounds. Journal of Experimental Botany, Oxford, v. 37, n. 1, p. 129-134, 1986.

RIVAS-SAN VICENTE, M.; PLASENCIA, J. Salicylic acid beyond defence: its role in plant growth and development. Journal of Experimental Botany, Oxford, v. 62, n. 10, p. 3321-3338, 2011.

RAIJ, B. V. et al. Recomendações de adubação e calagem para o Estado de São Paulo. 2. ed. Campinas: IAC, 1996. (Boletim técnico, 100).

RAIJ, B. V. et al. Análise química para avaliação da fertilidade de solos tropicais. Campinas: Instituto Agronômico, 2001.

SENARATNA, T. et al. Acetyl salicylic acid (aspirin) and salicylic acid induce multiple stress tolerance in bean and tomato plants. Plant Growth Regulation, Dordrecht, v. 30, n. 2, p. 157-161, 2000.

SHAKIROVA, F. M. et al. Changes in the hormonal status of wheat seedlings induced by salicylic acid and salinity. Plant Science, Amsterdam, v. 164, n. 3, p. 317-322, 2003.

SINGH, B.; USHA, K. Salicylic acid induced physiological and biochemical changes in wheat seedlings under water stress. Plant Growth Regulation, Dordrecht, v. 39, n. 2, p. 137-141, 2003.

SOUZA, G. M.; OLIVEIRA, R. F.; CARDOSO, V. J. M. Temporal dynamics of stomatal conductance of plants under water deficit: can homeostasis be improved by more complex dynamics? Arquivos de Biologia e Tecnologia, Curitiba, v. 47, n. 3, p. 423-431, 2004.

TATAGIBA, S. D. et al. Trocas gasosas e potencial da água em clones de eucalipto submetidos ao déficit hídrico. Engenharia na Agricultura, Viçosa, v. 15, n. 3, p. 212227, 2007. 